\title{
People awareness about diabetes disease and its complications among aged 18 years and older in Bushehr port inhabitants (Iran)
}

\author{
Ali Reza Soltanian ${ }^{\text {a,* }}$, Fatemeh Bahreini ${ }^{\text {b }}$, Mohammad Afkhami-Ardekani ${ }^{\text {c }}$ \\ ${ }^{a}$ Department of Epidemiology and Biostatistics, Hamedan University of Medical Sciences, \\ Zipcod: 4171, Str. Shariat, Hamedan city, Iran \\ ${ }^{\mathrm{b}}$ Department of Health, Bushehr University of Medical Sciences, Iran \\ ' School of Medical Sciences, Yazd University of Medical Sciences, Iran
}

\section{KEYWORDS}

Awareness;

Diabetes;

Bushehr port;

Blood sugar;

Iran

\section{Summary}

Introduction: One of the most prevalent metabolic disease is diabetes and it can lead to enormous medical as well as socio-economic consequences.

The Iranian diabetes population is estimated to be around 1.5 million. Studies show that approximately half of the people with type 2 diabetes (T2DM) are undiagnosed and thus unaware that they have the disease. This lack of awareness can lead to presentation with complications and its consequences.

The aim of this survey was to determine the level of population awareness in Bushehr port, based on the available education programs.

Material and methods: The cross-sectional study was assessed upon 719 subjects aged over 18 years old, without diabetes and inhabitant in Bushehr port in 2005. Multistage random simple sampling was used in this study. A questionnaire was prepared with validity checked by researchers in Yazd Diabetes Research Center and reliability alpha-cronbach $=75 \%$.

The questionnaire was included 39 questions: demographics indices, fundamentals about diabetes, its presenting signs and symptoms, the early and late complications, means of management as well as looked into the source of the information. The data was analyzed with independent $t$-test, Pearson's correlation coefficient, ANOVA and multiple-regression models by SPSS package ver. 10.05 .

Results: In this study, 719 subjects (417 male and 302 female) that mean age was $40.13 \pm 11.48$ years $(40.8 \pm 12.93$ for male and $39.19 \pm 9.03$ for female) were assessed. The male awareness rate was more than of female $(P=0.001)$. There was indirect relation between subjects' awareness and their age $(r=-0.203$, $P=0.001)$. There was direct relation between awareness and the level of education of subjects $(P=0.01, r=0.07)$. The mean of awareness scores of subjects was not

\footnotetext{
* Corresponding author.

E-mail address: a_sultanian@yahoo.com (A.R. Soltanian).
} 
same between singles and married $(P=0.042)$. Studies population awareness about fundamental diabetes disease, primary symptoms, early complications, delay complications, diet awareness was low and about controlling methods of diabetes was high.

Conclusion: The results indicate that most subjects' awareness about fundamental and complications of diabetes disease were low, so the people need more education about diabetes.

(C) 2007 Published by Elsevier Ltd on behalf of Diabetes India.

\section{Introduction}

One of the most common metabolic disorder is diabetes mellitus, and it causes hyperglycemia, because of absolute or relative deficiency of insulin [1].

Gestational diabetes is a variety of diabetes that happened pregnant women, and was shown in 3-5\% total of pregnancies [2]. Iranian diabetes population is estimated to be more than 1.5 million [3]. Diabetes is one of the most important causes of blindness in aged $20-74$ years old [4]. Also, about $40 \%$ of aged 40-74 years old (approximately 41 million) are in primary processes diabetes disease, and risk of type II diabetes is rising now [5]. Shirkani and Nabipour reported that age-adjusted prevalence of diabetes in Bushehr port was 9\% [6].

Diabetes disease imposes expensive cost on community, as it has $\$ 44$ billion direct cost and $\$ 55$ billion indirect cost in USA [7]. Yearly cost of direct diabetes disease in Iran (pay for visit physicians) is about $\$ 10$ billion [8]. Amini et al. estimated cost of any one of diabetic patients was equal $7,893,868.3$ Rials in Iran [9].

Some studies in Tehran and Bushehr indicated that approximately half of the diabetics population were not awareness of their disease $[6,10,11]$. Also, other studies show that only two-thirds of the people who have diabetes know that have it, the other one-thirds who have diabetes have not been diagnosed $[12,13]$.

Because lack of awareness can lead to development of diabetes and increase cost of treatment, so one must increase people awareness. Thus, the aim of this survey was to determine the level of public awareness among community in Bushehr port in Iran.

\section{Materials and methods}

The population-based cross-sectional study was assessed upon 719 subjects have aged 18 years and older, without diabetes disease in Bushehr port in Iran. In this study, responders do not participate in
MONICA project in Bushehr (MONICA project is a program that examine status of stroke and cardio vascular disease among inhabitants in Bushehr Province, and one of its aim is identification of individuals that have hyperglycemia and consult them). Multi-stage random sampling technique was used in this study, trained subjects conducted face-to-face interviews using a questionnaire was prepared with reliability alpha-cronbach $=75 \%$ and validity checked by Yazd Diabetes Research Center.

The questionnaire included: demographic variables (such as age, sex, educational level, marital status and family history of diabetes disease), fundamental diabetes disease (nine questions), primary symptoms (six questions), early and late complications (three and six questions, respectively), diabetes diet (10 questions), controlling methods (four questions) and source of information. Because some of participants were illiterate, they couldn't read questions themselves. Thus, questions were read by questioners. In order to avoid of sampling bias, the questioners went to responders homes at 7 p.m. to 9 p.m. Also, in case of primary non-responding, they would come back again to the responder homes.

We used independent $t$-test to compare measure of awareness score and Pearson's correlation coefficient to related between continue variables. Also we used one-way analysis of variance to compare the mean values across groups. For evaluation effect variables on awareness score as a continuous variable, multiple-regression models was used with measure of age, marital status, educational level and sex as independent variables and family history of diabetes disease as covariate. Statistical analysis was performed by SPSS win 10.5 (SPSS Inc., Chicago, IL). We give $95 \%$ confidence intervals for differences between means and estimates of multiple-regression models coefficients.

\section{Results}

In this survey 719 persons assessed aged 18 years and older, without diabetes and inhabitant in Bushehr port, that 417 persons were male (58\%) and 302 
persons were female (42\%). The $\mu \pm$ S.D. of age for total studies population was $40.13 \pm 11.48$ ( $40.8 \pm 12.93$ for male, $39.19 \pm 9.03$ for female). Of the studies population, $16 \%$ was less than 30 years, $37.1 \%$ was between 30 and 39 years, $27.5 \%$ was between 40 and 49 years and $19 \%$ was 50 years and older. In this survey 89 (12.3\%) of all responders had family history of diabetes disease (types I or II) that was not significantly different between them, and $223(31 \%)$ subjects were single. This study show that there was indirect relation between subjects' awareness scores and their age $(r=-0.203$; $P=0.001$ ).

This study shows that awareness score responders with family history of diabetes disease are same awareness score respondents without family history of diabetes $(P=0.096)$. Table 1 shows male awareness score was more significantly than of female $(P=0.001)$.

Table 1 shows that there was direct relation between awareness score and education of people $(r=0.07, P=0.01)$. In this survey six primary symptoms were asked that over half of subjects (52.3\%) knew none of them and $47.7 \%$ of subjects at least knew one, consisting, $29.1 \%$ and $0.83 \%$ subjects, respectively, knew weakness and nocturia, as the most and the least primary symptoms of diabetes disease. Only $19.3 \%$ and $8.5 \%$ of respondents at least knew two and three primary symptoms, respectively. Of the three early complications were asked, that $228(31.7 \%)$ of subjects knew none of them and $68.3 \%$ of subjects at least knew one (approximately $58 \%$ of subjects told that hyperglycemia can be early complication of diabetes). Of the six late complications that were inquired about $108(20 \%)$ of subjects knew none of them and $80 \%, 34 \%$ and $17 \%$ of subjects knew one, two and three late complication of diabetes disease. Approximately two-third of subjects (66.6\%) knew stroke and $\mathrm{Ml}$, as a late complication and nobody knew of erectile dysfunction as a complication.

Only $7.9 \%$ of all women and $9.2 \%$ of all studies subjects knew gestational diabetes. Controlling methods included: sports and increased physical activity, injection with insulin, using tablets of blood sugar and diet. Subjects (4.9\%) knew none of them and over $10 \%$ of subjects did not know about exercise and diet as controlling methods of diabetes disease.

In the questionnaire, 10 diet questions were asked. Six $(0.8 \%)$ of subjects knew none of them and $52.3 \%$ and $21.2 \%$ of subjects knew at least five and six diet-related questions, respectively. The most mentioned diet that subjects counted as

Table 1 Frequency of respondents and mean \pm S.D. of awareness scores among Bushehr port

\begin{tabular}{|c|c|c|c|c|}
\hline Variable & $N$ & Mean \pm S.D. & $\begin{array}{l}P \text {-value of } t \text {-test } \\
\text { and ANOVA analysis }\end{array}$ & $\begin{array}{l}P \text {-value of } \\
\text { multiple-regression } \\
\text { analysis }\end{array}$ \\
\hline \multicolumn{5}{|l|}{ Sex } \\
\hline Male & 417 & $17.98 \pm 6.01$ & & \\
\hline Female & 302 & $15.59 \pm 6.42$ & 0.001 & 0.001 \\
\hline Total & 719 & $16.96 \pm 6.29$ & & \\
\hline \multicolumn{5}{|c|}{ Family history of diabetes disease } \\
\hline Yes & 89 & $17.79 \pm 4.7$ & & \\
\hline No & 630 & $16.85 \pm 6.48$ & 0.096 & 0.11 \\
\hline \multicolumn{5}{|l|}{ Age group } \\
\hline$<30$ & 117 & $19.44 \pm 5.51$ & & \\
\hline $30-39$ & 267 & $16.51 \pm 6.06$ & 0.001 & 0.003 \\
\hline $40-49$ & 198 & $18.15 \pm 6.33$ & & \\
\hline$\geq 50$ & 137 & $15.01 \pm 4.99$ & & \\
\hline \multicolumn{5}{|l|}{ Marital status } \\
\hline Married & 496 & $16.64 \pm 6.35$ & 0.042 & 0.042 \\
\hline Single & 223 & $17.69 \pm 6.12$ & & \\
\hline \multicolumn{5}{|l|}{ Educations } \\
\hline Illiterate & 110 & $15.25 \pm 6.21$ & & - \\
\hline Primary & 215 & $14.00 \pm 5.67$ & & 0.47 \\
\hline Secondary & 137 & $18.91 \pm 5.62^{a}$ & 0.001 & 0.001 \\
\hline High school & 131 & $18.48 \pm 6.03^{a}$ & & 0.013 \\
\hline Upper & 126 & $19.83 \pm 5.83^{a}$ & & 0.001 \\
\hline
\end{tabular}

The mean difference is significant the 0.05 level.

a Post hoc multiple comparisons Tukey's test is used for significance in educational level. 
cause of diabetes disease were sweet fruits $(79.4 \%$ for example: apple, grapes, etc.) and the leastmentioned ones were sausage.

The information source of $47.3 \%$ of subjects was community based (28.2\% of women, $19.1 \%$ of men), $27.1 \%$ radio and T.V. programs, $14.1 \%$ physicians, $2.1 \%$ study of medical books, $1.5 \%$ was magazines and newspaper, $7.9 \%$ was other sources (major information source among women and men was community based, radio and T.V. programs, respectively).

\section{Discussion}

This study shows that approximately two-third of subjects $(64 \%)$ have low awareness about diabetes disease (their awareness scores lower than mean of total score that minimum and maximum of scores equal 0 and 39 , respectively in our questionnaire). In this survey it is observed that over half of subjects knew none of primary symptoms, and only $47.4 \%$ of them at least knew one primary symptoms of diabetes disease. Therefore, awareness about primary symptoms was low and insufficient. Also approximately $32 \%$ and $20 \%$ of responders knew none of early and late complications of diabetes disease. One of the late complications of diabetes disease is stroke and $\mathrm{Ml}$, that $66.6 \%$ of responders have information about them. The rate is relatively high, and it was maybe MONICA interventional project in Bushehr, ongoing since 2003, which may be the result for this. In MONICA project, FBS of participants was measured and necessary consulting gave them the information. In study by Ahmed-Khan, that was carried out on Saudi diabetic patient registered at Najran General Hospital, showed knowledge about the chronic complications of diabetes was dramatically low and $56 \%$ of responders had adequate knowledge about the symptoms of hypoglycemia [14]. If stroke and $\mathrm{MI}$ complications were eliminate from the questions, our results would be same as Ahmad-Khan's study, so that awareness of people about early and late complications of diabetes disease in both studies. Some of findings in this study are not similar to in Yazd and Tehran study [15,16]. In Yazd study, subjects awareness about fundamental diabetes, primary symptoms, late complications was higher than this study results [15].

In our study, awareness of women about gestational diabetes is very low, so that, only $7.9 \%$ of women knew gestational diabetes. Since, in the study number of women that are married, is relatively high, therefore, it can lead to dangerous consequences.

Our study shows that awareness of subjects about dietary was moderate, because approximately half of subjects (52.3\%) knew at least six dietaries, but about controlling methods was high $(95.1 \%$ of subjects knew at least one controlling methods, such as, diet, exercise, oral tablets and insulin injections). In Bushehr port, most of healthy programs were implied at T.V. and radio. The programs mostly discuss about diet and exercise.

This study shows male awareness mean was more than female $(P<0.001)$. In the Yazd and Tehran Diabetes Research Center study, with respect to survey people awareness were observed that there was significant difference between males awareness and females awareness $[15,16]$. The results of study on Saudi in 1998 showed that males were more aware than females [14].

Findings showed that over $72 \%$ of all responders were not aware that absolute or relative deficiency of insulin was cause of diabetes disease and approximately $93 \%$ of subjects were not aware normal range of blood sugar. The other study showed that only one-thirds of responders were aware of their blood glucose value and women are more likely than men to knew their blood glucose value [17].

Our study indicate that $49.1 \%$ of responders know decrease in visual acuity, as late complications of diabetes. In Australia a study that was carried out among the general population of Australian showed a higher level of awareness of the ocular effects of diabetes knew that diabetes could be sight threatening [18].

The present study and the other were shown that there was significant direct association between people awareness rate and their education $[19,20]$. In this study and results of Yazd and Tehran study were observed $47.3 \%, 40.2 \%$ and $49 \%$ of people respectively got their awareness by means of community. The most of people get diabetes disease information were not exact and complete, therefore, maybe it was cause of decrease people awareness about diabetes.

This study shows that people awareness in Bushehr port was approximately same as people awareness in big Iranian cities and some population $[19,20]$.

The study shows that subjects awareness about the fundamentals of diabetes is not high and accessible, but awareness about means of control was relatively higher. Thus, people need more education about diabetes its primary symptoms and its complications.

\section{Acknowledgements}

We thank Akram Barzegari and Elham Seidaly for help with various aspects of this study. 


\section{References}

[1] De Fronzo RA. Pathogenesis of type 2 diabetes: metabolic and molecular implications for identifying diabetes genes. Diabetes Rev 1997;5:177-270.

[2] Larijanii B, Zahedi F. Epidemiology of diabetes mellitus in Iran, Iran J Diabetes Lipid Disorders 2001-2002;1(1) FallWinter:1-8.

[3] Azizi F. Epidemiology of diabetes in Iran. In: Proceedings of the new approaches seminar in diabetes education and treatment; 2001. p. 7-9.

[4] Aiello LP, Gardner TW, King GL, Blankenship G, Cavallerano JD, Ferris 3d FL, et al. Diabetic retinopathy. Diabetes Care 1998;21:143-56.

[5] Feds Launch Diabetes Awareness Campaign. 2005;6(29) January 28. Available at http://www.applesforhealth.com.

[6] Shirkani A, Nabipour I. Prevalence of non-glucose tolerance and risk factors coronary in Bushehr, Iranian Journal of Endocrinology and Metabolism. In: Proceedings of 5th International Endocrinology Diseases Congress; September 1999.p. 75.

[7] Songer TJ, Ettaro L. Studies on the cost of diabetes. Atlanta, USA: Centers for Disease Control and Prevention; 1998.

[8] Hossein-Nezhad A, Larijani B. Cost analysis of screening and diagnosis methods in gestational diabetes. Iran J Diabetes Lipid Disorders 2001-2002;1(1) Fall-Winter:31-40.

[9] Amini M, Khadivi R, Haqhiqhi S. Costs of type 2 diabetes mellitus in Isfahan-Iran. Iran J Endocrinol Metab Summer 2002;4(2):97-104.

[10] Navaii L, Kimiagar M, Azizi F. Prevalence of diabetes and IGT and comparison between results of screening and OGTT methods in glucose tolerance disorders. J Res Med 1995;2(1):85-96.
[11] Aosfoory A, Nabipour I, Fakhrzadeh H, Rayani M, Haqhshenas $M$. Prevalence of non-insulline dependent diabetes and glucose tolerance disorders in population aged 30-64 Bushehr Port. Iran South Med J 1997;1(1):209-17.

[12] Meck Higgins ML. Diabetes awareness and management, promot healthier and safer lives. Kansas State University; 2000.

[13] More diabetes awareness needed. 2004;5(49) June 4. Available at: http://www.applesforhealth.com.

[14] Latif Ahmed Khan, Sarosh Ahmed Khan. Level of knowledge and self-care in diabetics in a community hospital in Najran. Available at: http://www.kfshrc.edu.sa/annals/203_204/ 99-177R.htm.

[15] Afkhami Ardakani Mohammad, Yadollahi Ali Reza, AbolHasani Ahmad. Awareness rate of Azad City inhabitants about diabetes. J Shahid Sadouqhi Univ Med Sci Health Serv Winter 1998;8(1):11-4.

[16] Larijani Baqher. A study on awareness rate of Tehran City inhabitant about diabetes. In: Proceedings of The 2 nd International Endocrinology Diseases Congress; September 1993. p. $110-1$.

[17] Alexandria Va, Awareness of blood sugar critically lacking despite diabetes increase. American Diabetes Association survey Finds. Available at: http://www.diabetes.org/ for-media/2004-press-releases/03-23-04.isp.

[18] Schmid Katrina L, Schmid Leisa M, Pendersen Carol. Knowledge of the ocular effects of diabetes among the general population of Australia and members of diabetes Australia. Clin Exp Optometr 2003;86(2):91-103.

[19] Aranda Jr JM, Vazques R. Awareness of hypertension and diabetes in the Hispanic community. Clin Cornerstone 2004;6(3):7-15.

[20] Tessaro I, Smith SL, Ryo S. Knowledge and perceptions of diabetes in a Appalachian population. Prev Chron Dis April 2005.

Available online at www.sciencedirect.com

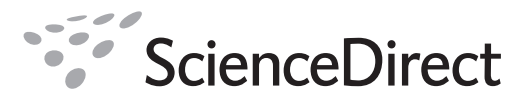

